\title{
Reference and definiteness
}

Cristina Guardiano cguardiano@unimore.it Università di Modena e Reggio Emilia
Giuseppe Longobardi longbard@units.it Università di Trieste

It has become increasingly clear since Longobardi $(1994,2003)$ that certain languages (e.g. Romance, but also Classical and Modern Greek, Bulgarian, Arabic (Fassi-Fehri 2003)...; henceforth 'strong D' languages) exhibit overt association of the referential content of nouns (proper names and referential generics) with D (either by overt N-to-D raising, e.g. of proper names, or by an arguably expletive article), others do not (e.g. English, but also probably the rest of Germanic, Celtic...; 'weak D' languages). From a number of scattered observation it can be suspected that a roughly analogous phenomenon arises with respect to another semantic property of DPs, namely definiteness: in certain constructions of some languages, but crucially not in the closely comparable constructions of others, the definite reading of nominal arguments seems to depend on the overt association of some morphosyntactic material with $\mathrm{D}$ (fronting to $\mathrm{D}^{\circ}$ or SpecD). Compare, in fact, the following contrasts:

(1) a. Semitic Construct State (N-Gen-AP) vs. Germanic Saxon Genitive (Gen-AP-N)

(Longobardi 1996)

b. Semitic Construct State (N-Gen-AP) vs. Celtic Construct State (AP-N-...Gen) (cf.

Rouveret 1994)

c. Rumanian $(\mathrm{N}+$ def-AP) vs. Scandinavian (...AP-N+def) enclitic definiteness suffixes

d. Bulgarian $(A P+$ def-N) vs. Icelandic $(A P-N+d e f)$ definiteness suffixes in the presence of APs

e. Classical Greek genitive (Art-Gen-Adj-N) vs. Germanic Saxon Genitive (Guardiano 2003)

Such cases will be illustrated in some detail. Consider, now, that strong D languages as defined above seem to significantly coincide with those where definiteness-bearing nouns or adjectives are overtly fronted to the D area, while in supposedly weak D languages, ceteris paribus, no such process appears. In other words, the distribution of definiteness-triggered and reference-triggered raising operations tends to be typologically syncretic. We will thus argue for the following descriptive generalization and show that the behavior of a wide variety of definite descriptions can be derived by virtually the same axioms (principles and parameters) already proposed in Longobardi (2003) for the pattern of referential nominal expressions:

\section{(2) Definiteness is overtly associated with D iff reference is}

Therefore, the syntax of reference and that of definiteness will be argued to be crosslinguistically governed by a single, deep, parameterization. Finally, it must be noticed that the most classical manifestation of definiteness marking, namely the non-enclitic definite article, such as English the, appears to escape such parameterization: its distribution seems very similar mutatis mutandis in e.g. Italian and English, and probably also other languages of either type. We will thus propose, in agreement with Bernstein (2004), that the so-called definite article is not a lexical manifestation of the category 'definiteness' but rather of other inflectional categories independently related to the category D. If all these hypotheses turn out to be correct, it can be concluded that the parameterization of the interpretive properties of $\mathrm{D}$ irst put forth in Longobardi (1994) (or, cast in different terms, in Chierchia 1998) to account for the semantic mapping of bare nouns and proper names is actually responsible for crosslinguistic distinctions in a much larger class of nominal constructions. 


\section{Reference and definiteness}

\section{A parametric generalization: Strong/Weak D}

Longobardi (1994, 2003a): certain languages (henceforth 'strong D' languages) overtly associate both object- and kind-referential nouns (proper names and referential generics) with D (either by movement (N-to-D chain), or by an arguably expletive article (N-to-D CHAIN)), other languages associate neither (henceforth 'weak D' languages).

\section{Italian:}

(1) a. Lunedì scorso è stato un giorno difficile Monday last was a hard day

b. * Scorso lunedì è stato un giorno difficile Last Monday was a hard day

c. Lo scorso lunedì è stato un giorno difficile The last Monday was a hard day

(2) Madame Curie ha scoperto *(il) radio Madame Curie discovered radium

(3) a. Core Generalization (Longobardi 2003a): in Romance N-to-D chain/CHAIN iff reference (i.e. the two constant interpretations: proper names and kind names)

b. Economy principle: no chain/CHAIN is more economical than any chain/CHAIN

\section{English:}

(4) a. Last Monday was a hard day

b.* Monday last was a hard day

(5) Madame Curie discovered radium

(6) Parameter: Italian: +(3)a (strong D)/English: -(3)a (weak D)

\section{Strong D languages}

\section{Rumanian:}

(7) Proper names untestable: require an article whenever modified by an adjective

(8) Madame Curie a descoperit radium-*(ul)

Madame Curie discovered radium-the

(9)

\begin{tabular}{|l|c|c|}
\hline & Italian & Rumanian \\
\hline$\underline{\text { enclitic def }}$ & - & + \\
\hline
\end{tabular}

\section{Greek:}

(10) a. H Rwvmh eivnai h proteuvousa th" Italiva"

The Rome is the capital of the Italy

b. * Rwvmh eivnai h proteuvousa th" Italiva"

Rome is the capital of the Italy 
(11) H Mantavm Kiouriv anakavluye *(to) ravdio

The Madam Curie discovered the radio

(12) a.* Oi/Polloiv elevfante" avsproi

The/Many elephants white

b. Oi/Polloiv avsproi elevfante"

The/Many white elephants

(13) If $\mathrm{N}$ does not raise to a high position (over adjectives), the only option to overtly relate $\mathrm{N}$ to $\mathrm{D}$ is an expletive article (CHAIN) for all proper names

\begin{tabular}{|l|c|c|c|}
\hline & Italian & Rumanian & Greek \\
\hline \pm enclitic def & - & + & - \\
\hline \pm N over A & + & + & - \\
\hline
\end{tabular}

\section{Ancient Greek:}

(15) a. ejpi; th/§ oijkiva/ th/§ $\Delta$ Agavqwno" (Symposium $174 \mathrm{~d} 7$ - e 1) $\quad \varnothing \quad \mathrm{N}$ At the house of Agathon

b. favnai to;n $\Delta$ Agavqwna Art N

...that the Agathon said

c. to;n diploußn "Erwta touß̧ton e[cein (Symposium 186 b 4) Art A N ...that the double-faced Eros has this (property)

d.* "Erwta diploußn touß̧ton e[cein

e.* diploußn "Erwta touß̧ton e[cein

$*_{\varnothing} \mathrm{N} \mathrm{A}$

$* \varnothing \mathrm{A} \mathrm{N}$

(16) a. ejpivskeyai poiß blevpwn oJ nomoqevth" ta; ojnovmata tivqetai (Cratylus 389 a 5-6)

see now what the lawgiver has in view in giving the names

kind

b. ojnovmata poiou§nte" (Cratylus 393 e 2)

making (some) names

indefinite

(17) a. eij ejgw; pavlai ejpeceivrhsa pravttein ta; politika; pravgmata (Apology of Socrates 31 d 7-8) Art A N

if I had long since begun to be involved in the political affairs

b. * ... pravttein ta; pravgmata politikav

*Art N A

$$
\text { e[tucon ga;r proçelqw;n ajndri; o\}" ... (Apology of Socrates } 20 \text { a 4) ø } \mathrm{N}_{\mathrm{sg}}
$$
I happened to run into a man who...

Crisma (1999) on null Ds:

(19) a. Ds must be identified, among other features, w.r.t. \pm count, \pm def only if the latter are grammaticalized in the language

b. \pm count is identified iff - def is

c. Identification of + count:

i) by an overt + count determiner/plural morphology

ii) by contextual identification (inheritance of count: Crisma 1999)

(20) Theorem: languages which do not grammaticalize the feature \pm count may have null 
Ds freely selecting count singular nouns as arguments (null articles)

(21) a. Null articles in this sense (i.e. licensing bare singulars, e.g. as indefinites, cf. (18)) can also be identified as expletive articles, though only with proper names (by (3)b above): Guardiano (2004)

b. Adjectives intervening between $\mathrm{D}$ and $\mathrm{N}$ apparently block the identification of such null expletive articles (a Minimality requirement on local identification?)

(22)

\begin{tabular}{|l|c|c|c|c|}
\hline & Italian & Rumanian & Greek & Anc. Grk \\
\hline \pm enclitic def & - & + & - & - \\
\hline \pm N over A & + & + & - & - \\
\hline \pm null art & - & - & - & + \\
\hline
\end{tabular}

\section{Bulgarian:}

(23) a. Rim

Rome

b.* Rim dreven

Rome ancient

c.* Dreven Rim

Ancient Rome

d. Drevn-iyat Rim

Ancient-the Rome

(24) Madam Curie otkri radij-*(a)

Madame Curie discovered the radium

(25) a. Namerix kniga.

Found-1sg book (with null article)

'I found a book'

b. * Namerix kniga cervena

Found-1sg book red

'I found a red book'

(26)

\begin{tabular}{|l|c|c|c|c|c|}
\hline & Italian & Rumanian & Greek & Anc. Grk & Bulg. \\
\hline \pm enclitic def & - & + & - & - & + \\
\hline \pm N over A & + & + & - & - & - \\
\hline \pm null art & - & - & - & + & + \\
\hline
\end{tabular}

\section{Arabic:}

(27) All nouns raise very high (past all modifiers) anyway, thus proper names provide no evidence. Kind names do (Fassi-Fehri 2003):

(28) ktashaf-at s-sayyidat-u kuurii *(r-)radyuum-a discovered-f. the lady-nom Curie the-radium-acc 


\begin{tabular}{|l|c|c|c|c|c|c|}
\hline & Italian & Rumanian & Greek & Anc. Grk & Bulg. & Arabic \\
\hline \pm enclitic def & - & + & - & - & + & - \\
\hline \pm N over A & + & + & - & - & - & + \\
\hline \pm null art & - & - & - & + & + & + \\
\hline
\end{tabular}

\section{Weak D languages}

Norwegian:

(30) a. Forrige mandag var en travel dag Last Monday was a busy day

b.* Mandag forrige var en travel dag

Monday last was a busy day

(31) Madame Curie oppdaget radium

Madame Curie discovered radium

\section{Icelandic:}

(32) a. Sí $\searrow$ asti mánudagur var erfi $\diamond$ ur dagur

Last Monday was difficult day

b. * Mánudagur sí $\diamond$ asti var erfi $\diamond$ ur dagur

Monday last was difficult day

(33) Marie Curie uppgötva $\searrow$ i radíum.

Marie Curie discovered radium

Welsh:

(34) Proper names irrelevant: always require an article if modified by an adjective (Rouveret 1994)

(35) Darganfu Marie Curie radiwm

Discovered Marie Curie radium

The other parameters crosscut, as expectable:

(36)

\begin{tabular}{|l|c|c|c|c|}
\hline & English & Norwegian & Icelandic & Welsh \\
\hline \pm enclitic def & - & + & + & - \\
\hline \pm N over A & - & - & - & + \\
\hline \pm null art & - & - & + & + \\
\hline
\end{tabular}

(37) a. the car

Eng

b. bil-en

Nor

c. bíll-inn

Ice

d. y car

Wel

'the car'

(38) a. a German car

Eng

b. en tyske bil

Nor

c. ПÁskur bill

Ice

d. car Almaenig

Wel

'a German car' 


\section{Definiteness}

In some constructions of certain languages, but crucially not in the closely comparable constructions of others, a definite reading depends on the overt association of some morphosyntactic material with $\mathrm{D}$ (fronting to $\mathrm{D}^{\circ}$ or $\mathrm{SpecD}$ ):

I. Arabic (Semitic) Construct State (N-Gen-AP) vs. English (Germanic) Saxon Genitive (GenAP-N) (cf. Longobardi 1996):

(39) a. daar-u r-rajul-i 1-waasica-t-u house the man's the large

b. The man's large house

II. Arabic (Semitic) Construct State (N-Gen-AP) vs. Welsh (Celtic) Construct State (AP-N...Gen) (cf. Rouveret 1994): unig blentyn y brenin only child the king

III. Rumanian $(\mathrm{N}+\mathrm{def}-\mathrm{AP} / \mathrm{AP}+\mathrm{def}-\mathrm{N})$ vs. Scandinavian $(\ldots \mathrm{AP}-\mathrm{N}+\mathrm{def})$ enclitic definiteness suffixes:

(41) a. Lup-ul Wolf-the

b. Hus-et House-the

c. Hús-i $\diamond$ House-the

Despite appearances Rumanian and Scandinavian suffixes are positionally very different:

(42) a. Lup-ul batrân (Rumanian) Wolf-the old

b. * Batrân lup-ul Old wolf-the

(43) a. Batrân-ul lup Old-the wolf

b.* Lup batrân-ul Wolf old-the

(44) a.* Hus-et store House-the large

(Norwegian)

b. * Store hus-et Large house-the

(45) Det store hus-et The large house-the

(46) a.* Hús-i $i$ stora (Icelandic) House-the large 
b. Stora hús-i $\diamond$

Large house-the

(47) a.* Kniga-ta cervena

Book-the red

(Bulgarian)

b. * Cervena kniga-ta

Red-the book

(42), (44), (46), (47) provide minimal comparisons.

Scandinavian (and presumably Bulgarian) suffixed Ns stay lower than APs, hence are not in $\mathrm{D}$ (cf. their - value at the $\mathrm{N}$ over A parameter). If $\mathrm{D}$ is empty the definite morphology of the suffix must be able to contextually identify it as + def in (41), hence neutralizing \pm count altogether (cf. (19)b).

By (3)b, intervening APs in Norwegian (44) must block local identification: the extra determiner in $\mathrm{D}$ is then predictably required for the identification of + count in Norwegian, but not in Icelandic, which has null articles (hence the contrast (44) is related to that in (38)).

But now why does Icelandic differ from Bulgarian (cf. below)?

IV. Bulgarian $(A P+d e f-N)$ vs. Icelandic (AP - N+def) definiteness suffixes in the presence of APs:

(48) Cervena-ta kniga

Red-the book

Rau $\diamond$ u bækurnar

Red books-the

(from Sigurdsson 2005)

$(50)$

\begin{tabular}{|l|c|c|}
\hline & Bulgarian & Icelandic \\
\hline \pm enclitic def & + & + \\
\hline \pm N over A & - & - \\
\hline \pm null art & + & + \\
\hline \pm strong D & + & - \\
\hline
\end{tabular}

V. Classical Greek genitive (Art-Gen-AP-N) vs. Germanic Saxon Genitive (cf. Guardiano 2003). Prenominal genitive does not involve definiteness inheritance, all other things being virtually equal in the DPs:

(51) a. to; th§̧ povlewç koino;n ajgaqovn

(Laws 800 a 5)

the the city's common good

'the common good of the city'

b. th§̧ povlewç koino;n ajgaqovn

the city's common good

'a common good of the city' 


\section{Definiteness and reference}

Strong D languages, as defined above w.r.t. overt fronting of reference-bearing nouns, significantly coincide with those where definiteness-bearing nouns or adjectives are overtly fronted to the D area, while in supposedly weak D languages, ceteris paribus, no such process appears:

(52) a. Strong reference: It, Rum, Blg, Grk, Arabic

b. Strong definiteness: Rum, Blg, Grk, Arabic

(53) a. Weak reference: Eng, Norw, Icel, Welsh

b. Weak definiteness: Eng, Norw, Icel, Welsh

I.e., the distribution of definiteness-triggered and reference-triggered chains tends to be typologically syncretic.

Generalization:

(54) Definiteness is overtly associated with D iff reference is

Therefore, the syntax of reference and that of definiteness are crosslinguistically governed by a single, deep, parameterization. Thus, the behavior of a wide variety of definite descriptions can be derived by virtually the same axioms (principles and parameters) already proposed in Longobardi (2003a) for the pattern of referential nominal expressions:

Denotation Hypothesis: Individuals are denoted in D

Licensing condition: Arguments denote individuals, as constants or variables

The conjunction of (55)-(56) yields (58) (which is independently well supported by argument/non-argument asymmetries in Romance: Longobardi 2003a) as a theorem:

A 'nominal expression' is an argument only if it is introduced by a category D (cf. Szabolcsi (1987), Stowell $(1989,1991)$ (N may denote properties, not individuals)

Definitions:

(59) a. Constants have a fixed referential value, thus denote one and only one entity (kind or object)

b. Variables are bound by (coindexed with) an operator and range over a set of values, thus denoting a set of entities (kinds -for taxonomic readings- or objects)

(60) a. an argument is a constant iff $D$ contains $\alpha, \alpha$ a lexically referential expression ${ }^{1}$ :

b. an argument is a variable iff $\mathrm{D}$ contains (the index of) an operator

In (60)a, the argument will denote whatever kind/object $\alpha$ refers to; for (60)b, binding may be selective (with an operator in $\mathrm{D}$ : definite/indefinite descriptions, quantified phrases...) or unselective (bare nouns, with empty D bound e.g. by Ex or Gen operators). The two subcases of (60)b may fall together under Dobrovie Sorin's (1994) DR, derivationally creating an empty category in D (Laca, Rothstein, Delfitto, Kamp p.c.).

\footnotetext{
1 An actual noun, pronoun or demonstrative (or equivalently an expletive article linked to the noun in a CHAIN in Chomsky's 1986 sense)).
} 


\section{The definite article}

Problem:

(61) the non-enclitic definite article, such as English the, appears to escape such parameterization: its distribution seems very similar mutatis mutandis in e.g. Italian and English.

Longobardi (2004): D is actually the Person head. Pronouns surface in D even in weak D languages because, unlike nouns, they intrinsically manifest the feature Person.

Proposal:

(non-enclitic) Definite articles (and some other lexical determiners) intrinsically contain the feature Person

In most European languages, such a feature Person on determiners is set on the default (Speaker, -Hearer) 3rd person value, but in others it is made visible by its variation in triggering agreement:

Las mujeres salimos con vosotros

The women go (1st pl.) out with you

Also cf. Bernstein (2004): the so-called definite article is not a lexical manifestation of the category 'definiteness' but rather of other inflectional categories independently related to the so-called category D.

\section{Conclusions}

The parameterization of the interpretive properties of D first put forth in Longobardi (1994) (or recast in slightly different, but empirically equivalent terms, in Chierchia 1998) accounts in a unified way for the semantic mapping of bare nouns and proper names and, at the same time, of many definite descriptions:

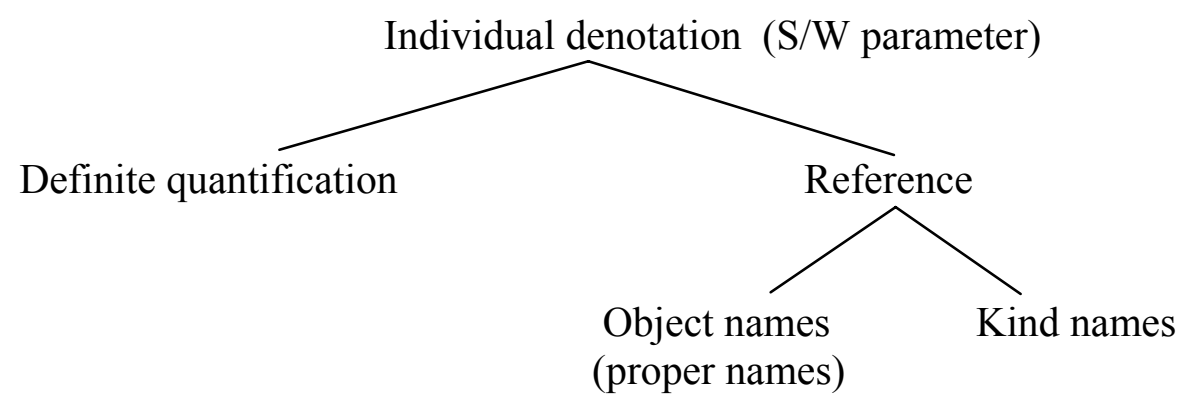

This empirical domain provides an excellent ground for an experiment in Modularized Global Parametrization (in the sense of Longobardi 2003b): few, closely interacting parameters studied in relatively many languages.

cguardiano@unimore.it

longbard@units.it 